\title{
AIRBORNE LIDAR MEASUREMENTS OF POLLUTION ABOVE THE OIL SANDS REGION IN NORTHERN ALBERTA
}

\author{
Monika Aggarwal $^{1 *}$, James Whiteway ${ }^{1}$, Jeffrey Seabrook ${ }^{1}$, Lawrence Gray ${ }^{1}$, Kevin B. Strawbridge ${ }^{2}$ \\ ${ }^{1}$ Centre for Research in Earth and Space Science, York University, Toronto, Ontario, M3J 1P3, \\ *Email:aggarwal@yorku.ca \\ ${ }^{2}$ Air Quality Processes Research Section, Environment Canada, Toronto, Ontario, M3H $5 T 4$
}

\begin{abstract}
Lidar measurements of ozone and aerosol were conducted from a Twin Otter aircraft above the oil sands region of northern Alberta. For the majority of the flights, significant amounts of aerosol were observed within the boundary layer, up to an altitude of $2.0 \mathrm{~km}$ above sea level (ASL), while the ozone concentration remained at background levels (30-45 ppb) downwind of the industry. On August $24^{\text {th }}$ the lidar measured a separated layer of aerosol above the boundary layer, at a height of $2.0 \mathrm{~km}$ ASL, in which the ozone mixing ratio increased to $70 \mathrm{ppb}$. Backward trajectory calculations revealed that the air containing this separated aerosol layer had passed over an area of forest fires. Directly below the layer of forest fire smoke, pollution from the oil sands industry was observed. Measurements of the backscatter linear depolarization ratio were obtained with a ground based lidar operated by Environment Canada within the oil sands region. The depolarization measurements aided in discriminating between the separate sources of pollution from industry and forest fires. The depolarization ratio was 5-6\% in forest fire smoke and $7-10 \%$ in the industrial pollution.
\end{abstract}

\section{INTRODUCTION}

A lidar system for tropospheric ozone and aerosol measurements was developed at York University for installation on aircraft $[1,2]$. This was installed on a Twin Otter aircraft in August 2013 for participation in a field campaign that was designed to study the air pollution from the oil sands extraction activities north of Fort McMurray, Alberta.

The chemical species of interest for the measurements was Ozone $\left(\mathrm{O}_{3}\right)$. Ozone is a secondary pollutant as it is produced from the photochemical reactions between $\mathrm{NO}_{\mathrm{x}}$ and VOCs in the presence of sunlight. Typically the background level of ozone in the troposphere is between 30 and $40 \mathrm{ppb}$. The exposure of crops and living organisms to ozone concentrations higher than the background levels can result in damage to biological tissue and decrease the rate of photosynthesis in plants [3].

The Twin Otter aircraft provided a platform for nadir directed lidar ozone and aerosol measurements above and downwind from the oil sands industry. The field campaign consisted of a total of five flights out of Fort McMurray during the period between August 22 and August 26, 2013. The flights were planned using meteorological analysis so that each flight path intersected the trajectory of air that had passed over the oil sands. The results from flight segments on August 23 and 24, 2013 are shown in this paper.

\section{MEASUREMENT TECHNIQUE}

A schematic diagram of the lidar is shown in Fig. 1. The fourth harmonic of a Q-switched $\mathrm{Nd}$ :YAG laser $(266 \mathrm{~nm}, 70 \mathrm{~mJ}$ per pulse, $20 \mathrm{~Hz}$ repetition rate) was focused into a gas cell filled with $140 \mathrm{PSI}$ of $\mathrm{CO}_{2}$ to generate pulsed light at wavelengths of $276 \mathrm{~nm}, 287 \mathrm{~nm}$ and $299 \mathrm{~nm}$ by stimulated Raman scattering [4] and then directed into the atmosphere along the zenith. The second harmonic output from the laser at a wavelength of $532 \mathrm{~nm}$ was also directed into the atmosphere. Backscattered light was collected with a $15 \mathrm{~cm}$ off axis parabolic mirror and two separate $1.5 \mathrm{~mm}$ diameter optical fibers positioned in the focal plane, $500 \mathrm{~mm}$ from the mirror, to form two 


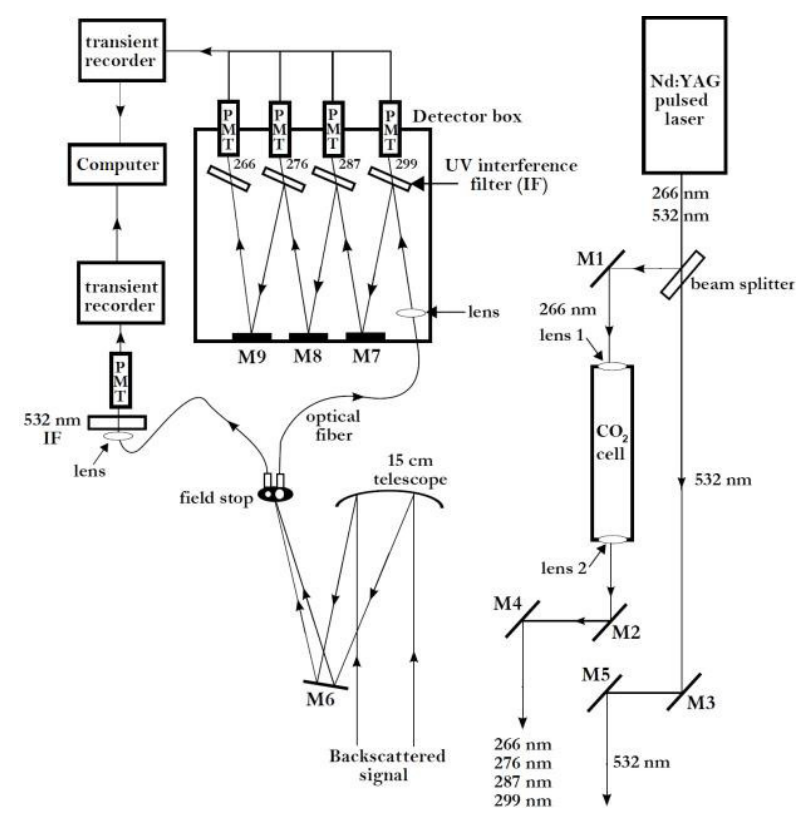

Figure 1: Schematic diagram of the lidar system for aircraft based measurements of aerosol and ozone.

separate receiver fields of view, each of width 3.0 mrad. The $532 \mathrm{~nm}$ signal was aligned to one of the optical fibers, while the UV wavelengths were aligned to the other fiber. The four UV wavelengths $(266,276,287$, and $299 \mathrm{~nm})$ were separated in the receiver using the transmittance and reflectance from interference filters having a bandwidth of $1 \mathrm{~nm}$ and tilted at an angle of 5 degrees. The backscatter signals were detected using photomultipliers to generate electrical signals that were recorded using photon counting for the weak signals from distances greater than $1.8 \mathrm{~km}$ and using analog to digital conversion for the strong signals in the near range. The raw data was recorded with a range gate of $3.75 \mathrm{~m}$ for the $532 \mathrm{~nm}$ signal and $7.5 \mathrm{~m}$ for the UV signals. The temporal integration was 10 seconds. During data processing the recorded backscatter signal profiles were averaged both spatially and temporally in order to reduce the measurement uncertainty.

The ozone concentration was derived by using the Differential Absorption Lidar (DIAL) technique [5]. For the lidar derived ozone measurements presented in this paper, the analog measurements of the 276/299 wavelength pair were used closer to the altitude of the aircraft and were combined with the photon counting measurements of the 266/299 wavelength pair for altitudes closer to the ground. Regions where extreme aerosol loading or clouds interfered with the ozone retrieval have been omitted in the analysis.

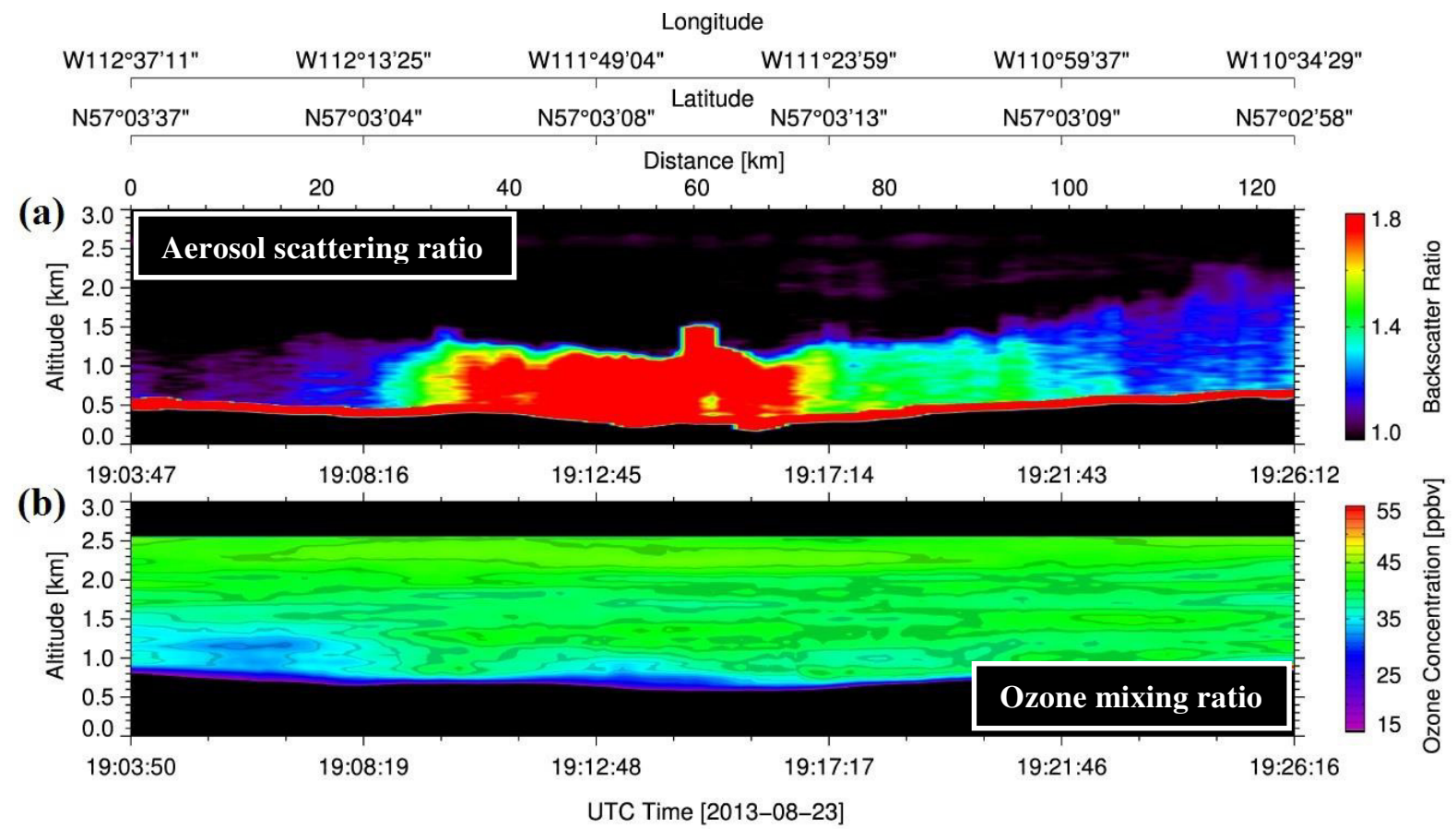

Figure 2: (a) The aerosol backscatter ratio and (b) the ozone mixing ratio derived from the lidar measurements for a flight segment on August 23, 2013. The height is above sea level. 


\section{OBSERVATIONS}

\subsection{Flight 2: August 23, 2013}

Measurements acquired during one leg on the flight of 23 August 2013 are shown in Fig 2. The flight path passed across the oil sands extraction industry from downwind (east) to upwind (west) at a constant latitude of $\mathrm{N} 57^{\circ} 03^{\prime}$. In Fig. 2(a), significant amounts of aerosol were observed over the industry and the height of the boundary layer is $1.5 \mathrm{~km}$ ASL. The corresponding ozone concentration along this flight segment is shown in Fig. 2(b). The ozone concentration remained consistent with background levels throughout the flight leg, with values ranging between 35 and 45 ppb. An increase in ozone concentration was not observed downwind from the industry.

\subsection{Flight 4: August 24, 2013}

Airborne lidar measurements to the north of Fort McMurray were made on August $24^{\text {th }}$ and the corresponding flight path is shown in Fig. 3.

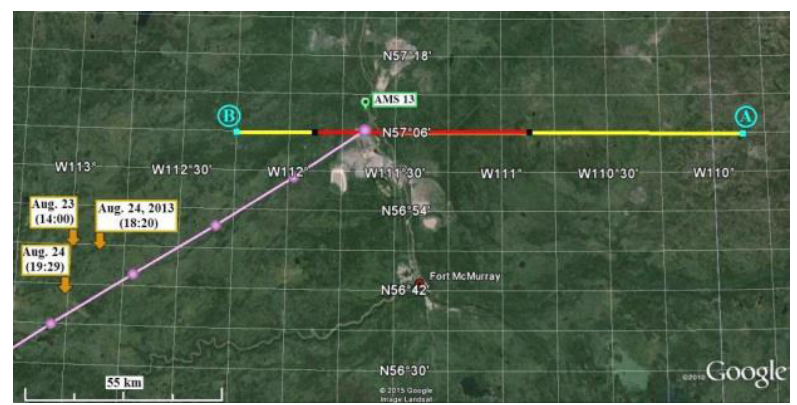

Figure 3: Flight segment A-B on Aug. 24, 2013 (produced on Google Earth). The red section along a flight leg represents the region where forest fire smoke was observed. The forest fires are depicted by orange arrows with the estimated start time beside each fire. A backward trajectory was initiated from an altitude of $2.0 \mathrm{~km}$ ASL at a time of 21:00 UTC on Aug. 24, 2013. The round marks along the trajectory represent a time interval of one hour. The green flag indicates the location of Environment Canada's ground based lidar.

In this flight leg, the Twin Otter started at point A (a distance of $\sim 90 \mathrm{~km}$ to the east of the oil sands industry) and travelled westbound to point $\mathrm{B}$ along a constant latitude of $\mathrm{N} 57^{\circ} 06^{\prime}$. Along this flight segment, the lidar observed a separated layer of material at an altitude of $2.0 \mathrm{~km} \mathrm{ASL}$ and pollution underneath as shown in Fig.4.
By using the HYSPLIT model [6], a backward air trajectory was initiated from an altitude of 2.0 $\mathrm{km}$ ASL at a time and location the lidar observed the separated aerosol layer. Figure 3 shows that the measured air passed over forest fires to the southwest of the flight track. In Fig. 4(a), the concentration of ozone in the forest fire smoke layer was measured to be up to $70 \mathrm{ppb}$. This is consistent with previous observations of in situ ozone measurements in North American forest fires [7].

Environment Canada's ground based lidar system observed the same layer of forest fire smoke at an altitude of $\sim 1.8 \mathrm{~km}$ ASL. In Fig. 4(c), the depolarization ratio in the forest fire smoke layer was measured to be $5-6 \%$. The depolarization ratio in the pollution from the oil sands industry at heights below $1.5 \mathrm{~km}$ had a larger depolarization ratio with values between $7 \%$ and $10 \%$. This provides further evidence that the layer with enhanced ozone had originated from forest fires rather than industrial pollution.

\section{CONCLUSION}

Air pollution above the Alberta oil sands region was studied with an airborne lidar system. Significant amounts of aerosol were observed up to an altitude of $2.0 \mathrm{~km} \mathrm{ASL}$, in which the ozone concentration remained at background levels (35$45 \mathrm{ppb}$ ). On the afternoon of August $24^{\text {th }}$, a layer of forest fire smoke was observed and this contained ozone concentrations of up to $70 \mathrm{ppb}$, which is significantly greater than the background.

\section{ACKNOWLEDGEMENT}

Financial support for this study was provided by FedDev Ontario, Environment Canada, the Natural Sciences and Engineering Research Council of Canada (NSERC), and the Canadian Foundation for Innovation (CFI). The authors would like to thank Mr. Cordy Tymstra from the Fort McMurray wildfire branch (under the Environment and Sustainable Resource Development of Alberta) for providing the forest fire locations. 

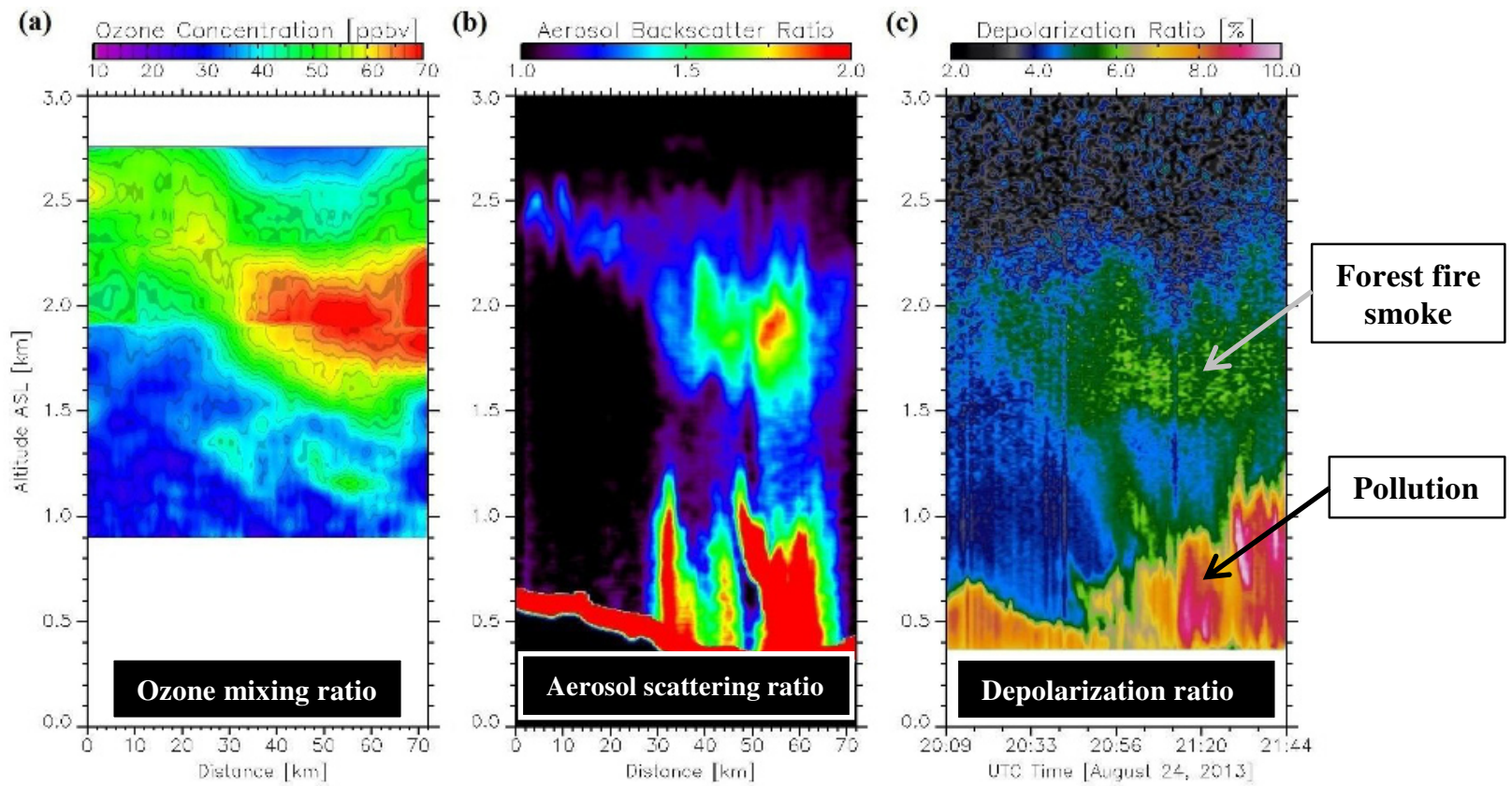

Figure 4: (a) The ozone mixing ratio and (b) the aerosol backscatter ratio derived from the lidar measurements along a section of the flight segment A-B (as shown in Fig. 3) where forest fire smoke was observed. Distance is along the red section of the flight segment in Fig. 3. (c) Depolarization ratio measurements taken by Environment Canada's ground based lidar system located at $57.15^{\circ} \mathrm{N}, 111.6^{\circ} \mathrm{W}$. This site is indicated as AMS 13 in Fig. 3.

\section{REFERENCES}

[1] Seabrook, J., J. Whiteway, J., R. Staebler, J. Bottenheim, L. Komguem, L. Gray, D. Barber, and M. Asplin, 2011: LIDAR measurements of Arctic boundary layer ozone depletion events over the frozen Arctic Ocean, J. Geophys. Res., 116, doi:10.1029/2011JD016335.

[2] Seabrook, J., J. Whiteway, L. Gray, R. Staebler, A. Herber, 2013: Airborne lidar measurements or surface ozone depletion over Arctic sea ice, Atmos. Chem. Phys., 13, $1-7$.

[3] Morgan, P. B., E. A. Ainsworth, S. P. Long, 2003: How does elevated ozone impact soybean? A meta-analysis of photosynthesis, growth and yield, Plant, Cell and Environ., 26, 1317 - 1328.

[4] Nakazato, M., T. Nagai, T. Sakai, Y. Hirose, 2007: Tropospheric ozone differential-absorption lidar using stimulated Raman scattering in carbon dioxide, Appl. Opt., 46, 2269 - 2279, doi:10.1364/AO.46.002269.
[5] Kovalev V. A., and W. E. Eichinger, 2004: Elastic Lidar: Theory, Practice, and Analysis Methods, New Jersey, USA: John Wiley \& Sons.

[6] Draxler, R.R. and G. D. Rolph. HYSPLIT (HYbrid Single-Particle Lagrangian Integrated Trajectory) Model access via NOAA ARL READY Website (http://www.arl.noaa.gov/HYSPLIT.php). NOAA Air Resources Laboratory, College Park, MD

[7] Aggarwal, M., 2011: Lidar measurements of forest fire smoke and stratospheric aerosol, Master of Science thesis, York University, Toronto, Canada. 